\title{
Application of an objective method of assessing intention tremor - a further study on the use of weights to reduce intention tremor
}

\author{
M. H. MORGAN, R. L. HEWER, AND R. COOPER
}

From the Department of Neurology, Frenchay Hospital, Bristol

SYNOPSIS Thirty-one patients with intention tremor due to a variety of causes were subjected to measurements of their intention tremor. The effect of varying amounts of lead weights on the amount of limb tremor recorded was noted. It is concluded that simple methods of treatment may be of benefit, and that an objective method of measuring intention tremor overcomes many of the difficulties of a clinical trial of this type. The method described yields quantifiable data which can be subjected to statistical analysis to help overcome the problem of variability. Bias in the results due to practice or fatigue effects has proved negligible. An optimum amount of lead, which was usually between 600 and $840 \mathrm{~g}$, has been noted.

Intention tremor, which accompanies lesions of the cerebellum and its connections, is known to give rise to neurological disability which may be severe and chronic and which poses an extremely difficult therapeutic problem. L-dopa, which has proved of such value in Parkinson's disease, has not been of similar help to patients with diseases of the cerebellum. Samra and his colleagues (1970) reported encouraging results of thalamic surgery for the relief of intention tremor but no report of similar successes from other centres has followed this publication. The possibility of using a simple mechanical damping device, such as weighting the limb, was initially investigated by Hewer et al. (1972). Objective evaluation of any form of treatment for intention tremor is clearly of importance, particularly in view of the marked variability exhibited by patients. The present study reports the use of one method of measuring intention tremor, and its application to the problem of evaluating the effect of weights on the performance of a simple motor task.

\section{METHOD}

PATIENTS Thirty-one patients were assessed, of whom 16 were female and 15 male. Their ages (Accepted 16 September 1974.) ranged from 8 to 69 years, with a mean of 42.1 years. Diagnoses were as follows: multiple sclerosis (nine patients), 'essential' tremor (five patients), cerebellar degeneration of unknown cause (four patients), Parkinson's disease (four patients), Friedreich's ataxia (three patients), trauma to the cerebellum and its connections (two patients), congenital lesions affecting the basal ganglia and cerebellar connections (two patients), cerebrovascular accident to the territory of the brain-stem (one patient), and cerebellar tumour (one patient).

The intention tremor was graded as very severe in two patients, severe in seven, moderately severe in 11 , and mild in 11 patients. Seventeen patients had no other neurological disability in the arms apart from intention tremor. Six patients had some motor deficit, of whom six had weakness, this being mild in four and moderate in two; seven had increased reflexes and two had increased tone. Eight patients had some mild sensory disability affecting the hands.

EXPERIMENTAL PROCEDURES The method of measuring intention tremor has been described by Morgan et al. (1975). Intention tremor was assessed both with and without weights. The weights were $60 \mathrm{~g}$ pieces of lead, measuring $8 \mathrm{~cm} \times 2 \mathrm{~cm}$, which fitted into calico wrist bands. These weights were placed round the wrists, over both the flexor and extensor surfaces. A series of 10 trials of movement toward a target button was recorded for each patient with and without $600 \mathrm{~g}$ of lead around the wrist. In some 
patients the measurements were made without weights before those with weights, and in some patients the reverse procedure was adopted. Patients were allocated randomly to these two groups. The purpose of this was to avoid any bias in the results which might have been due to a learning effect or to a fatigue effect in the latter trial.

Eight of the patients who exhibited intention tremor and no tremor of the outstretched arm were tested with a series of weights, $480 \mathrm{~g}, 600 \mathrm{~g}, 720 \mathrm{~g}$, $840 \mathrm{~g}$, and $960 \mathrm{~g}$ being tested. The order in which the weights were applied was again randomized. Ten trials with each of the weights were recorded, in addition to 10 trials without weights, both before and after these trials with weights. A two minute rest period was allowed between each sample run, and five minutes' practice before any recordings were sampled.

STATISTICAL PROCEDURES The results of the tremor measurements were normalized by taking square roots and were then subjected to an analysis of variance (Ferguson, 1966). The data from the various test situations could be compared by an F test on within and between groups variance (Ferguson, 1966). The raw data were available on punch cards, and the statistical calculations performed by computer.

\section{RESULTS}

Analysis of the tremor recordings, using the Linc 8 computer, yielded numerical indices of tremor activity before and after weighting the limb, and the values obtained from the 10 samples on each test occasion could be compared statistically (Table 1). The appropriate levels of significance of the differences between the means for the two test conditions are also shown. It can be seen that 20 of the 31 patients $(64.5 \%)$ showed a significant reduction of intention tremor with weights on the limb.

Variability in performance of the tests from time to time presented a serious difficulty in the evaluation of the results. However, a series of recordings was obtained which could then be subjected to statistical appraisal, using the analysis of variance described. A particular advantage of this analysis lies in the fact that a pooled variance from all groups of data recorded during the entire series of experiments may be used.

Although it has been noted that the design of
TABLE 1

COMPARISON OF TREMOR ACTIVITY WITH AND WITHOUT WEIGHTS, USING LINEAR ACCELEROMETER TO MEASURE TREMOR

\begin{tabular}{|c|c|c|c|}
\hline \multirow[t]{2}{*}{ Patients } & \multicolumn{2}{|c|}{$\begin{array}{l}\text { Mean value of tremor } \\
\text { activity in arbitrary } \\
\text { units (square roots of } \\
\text { original data) }\end{array}$} & \multirow[t]{2}{*}{$\begin{array}{c}\text { F ratios of variance between } \\
\text { groups to variance within } \\
\text { groups, to show alterations } \\
\text { with weights compared with } \\
\text { no weights }\end{array}$} \\
\hline & No weights & Weights & \\
\hline $\begin{array}{r}1 \\
2 \\
3 \\
4 \\
5 \\
6 \\
7 \\
8 \\
9 \\
10 \\
11 \\
12 \\
13 \\
14 \\
15 \\
16 \\
17 \\
18 \\
19 \\
20 \\
21 \\
22 \\
23 \\
24 \\
25 \\
26 \\
27 \\
28 \\
29 \\
30 \\
31\end{array}$ & $\begin{array}{r}17.61 \\
10.54 \\
30.64 \\
9.68 \\
11.89 \\
16.26 \\
14.78 \\
16.62 \\
10.48 \\
12.95 \\
16.74 \\
10.09 \\
11.34 \\
13.37 \\
11.75 \\
10.36 \\
9.70 \\
11.64 \\
11.61 \\
14.06 \\
16.09 \\
16.23 \\
21.17 \\
20.93 \\
21.93 \\
19.57 \\
13.12 \\
12.32 \\
29.96 \\
10.20 \\
12.19\end{array}$ & $\begin{array}{r}15.12 \\
8.25 \\
20.76 \\
8.47 \\
9.77 \\
13.07 \\
9.46 \\
11.48 \\
8.72 \\
10.60 \\
14.87 \\
6.54 \\
10.66 \\
14.06 \\
9.10 \\
7.70 \\
10.46 \\
11.35 \\
9.33 \\
10.84 \\
15.44 \\
14.39 \\
20.28 \\
14.79 \\
22.75 \\
15.54 \\
8.30 \\
10.06 \\
21.32 \\
11.68 \\
8.89\end{array}$ & $\begin{array}{c}3.09 \\
21.60 \dagger \\
72.13 \dagger \\
7.40^{*} \\
9.86 \dagger \\
8.04 \dagger \\
59.75 \dagger \\
41.97 \dagger \\
2.33 \\
13.54 \dagger \\
4.08 \\
33.36 \dagger \\
1.13 \\
1.24 \\
7.30^{*} \\
21.19 \dagger \\
1.52 \\
0.18 \\
11.24 \dagger \\
18.44 \dagger \\
0.31 \\
6.90^{*} \\
1.17 \\
56.28 \dagger \\
0.21 \\
13.72 \dagger \\
26.95 \dagger \\
5.19^{*} \\
21.92 \dagger \\
4.51^{*} \\
27.98 \dagger\end{array}$ \\
\hline
\end{tabular}

The mean values of tremor activity refer to means of square roots of the original data.

* Significant, P less than 0.05 .

† Significant, $\mathbf{P}$ less than 0.01 .

the experiment attempted to minimize the effect of practice, it was felt that this factor might possibly have influenced the results obtained. An alternative factor which might also have biased the results was fatigue, which would be expected to produce a deterioration in performance, represented by an increase in the tremor measurements. The data were therefore analysed to see whether either of these factors had produced a significant effect, by comparing, by analysis of variance, the results of the first five trials with the results of the last five trials for each test situation (Table 2). Without weights, only one patient showed a significant improvement during the second five trials, and only one other 
TABLE 2

COMPARISON OF FIRST FIVE TRIALS WITH FINAL FIVE TRIALS, TO TEST EFFECT OF PRACTICE AND FATIGUE ON AMOUNT OF TREMOR

\begin{tabular}{|c|c|c|}
\hline \multirow[t]{2}{*}{ Patients } & \multicolumn{2}{|c|}{$\begin{array}{c}F \text { ratios of variance between groups } \\
\text { to variance within groups }\end{array}$} \\
\hline & No weights & Weights $(600 \mathrm{~g})$ \\
\hline 1 & 5.03 & $6.24^{*} \downarrow$ \\
\hline 2 & 0.01 & 0.09 \\
\hline 3 & $6.16^{*} \downarrow$ & 2.33 \\
\hline 4 & 0.28 & 0.00 \\
\hline 5 & 3.72 & 0.09 \\
\hline 6 & 0.13 & 1.65 \\
\hline 7 & 0.01 & 2.72 \\
\hline 8 & 1.34 & 2.34 \\
\hline 9 & 0.05 & 0.07 \\
\hline 10 & 4.36 & 1.07 \\
\hline 11 & 0.21 & 1.91 \\
\hline 12 & 0.09 & 0.00 \\
\hline 13 & 1.68 & 0.63 \\
\hline 14 & 3.97 & 0.02 \\
\hline 15 & $12.87 \uparrow \uparrow$ & 0.05 \\
\hline 16 & 4.18 & 4.50 \\
\hline 17 & 0.03 & 1.47 \\
\hline 18 & 0.09 & 0.12 \\
\hline 19 & 1.63 & 0.03 \\
\hline 20 & 0.24 & 0.03 \\
\hline 21 & 0.34 & 0.04 \\
\hline 22 & 0.42 & 0.53 \\
\hline 23 & 1.26 & 0.60 \\
\hline 24 & 0.00 & 0.27 \\
\hline 25 & 0.54 & 0.29 \\
\hline 26 & 1.07 & 0.01 \\
\hline 27 & 0.02 & 0.24 \\
\hline 28 & 0.37 & $0.26^{*} \uparrow$ \\
\hline 29 & 2.57 & 0.64 \\
\hline 30 & 2.93 & $10.74^{*} \uparrow$ \\
\hline 31 & 1.63 & 0.47 \\
\hline
\end{tabular}

* Difference between means significant, $P$ less than 0.05 .

$\dagger$ Difference between means significant, $P$ less than 0.01 .

$\uparrow$ Increase in amount of tremor.

$\downarrow$ Decrease in amount of tremor.

\section{TABLE 3}

EFFECT OF WEIGHTS ON INTENTION TREMOR, AND F RATIOS (CALCULATED FOR 10 TRIALS WTTH EACH WEIGHT) FOR DIFFERENCE BETWEEN MEANS, COMPARING ORIGINAL TRIAL WITHOUT WEIGHTS AND WEIGHT AS LISTED

\begin{tabular}{ccccccc}
\hline Patient & $480 \mathrm{~g}$ & $600 \mathrm{~g}$ & $720 \mathrm{~g}$ & $840 \mathrm{~g}$ & $960 \mathrm{~g}$ & $\begin{array}{c}\text { Final } \\
\text { no weights } \\
\text { trial }\end{array}$ \\
\hline 1 & 0.67 & $8.04^{*}$ & 0.00 & 2.28 & 0.26 & 1.92 \\
2 & $10.0 \dagger$ & $59.75 \dagger$ & $50.38 \dagger$ & $52.46 \dagger$ & $37.66 \dagger$ & 3.44 \\
3 & $4.91^{*}$ & $41.97 \dagger$ & $49.86 \dagger$ & $88.20 \dagger$ & $44.63 \dagger$ & $21.00 \dagger$ \\
4 & 1.40 & 0.85 & $14.39 \dagger$ & 0.82 & 2.25 & 3.33 \\
5 & 0.29 & 0.29 & $4.53^{*}$ & 4.00 & 2.00 & 1.85 \\
6 & 0.25 & $13.54 \dagger$ & $11.24 \dagger$ & 3.94 & 1.41 & 0.01 \\
7 & 0.53 & $4.48^{*}$ & $20.88 \dagger$ & $8.14 *$ & 2.89 & $6.09 * \uparrow$ \\
8 & 4.25 & 2.11 & $9.86 \dagger$ & 2.24 & 1.56 & 0.64 \\
\hline
\end{tabular}

* Significant reduction of tremor, $P$ less than 0.05 .

+ Significant reduction of tremor, $P$ less than 0.01 .

* $\uparrow$ Significant increase of tremor, $P$ less than 0.05 . showed a significant deterioration. During the trials with weights one patient showed an improvement during the second five trials and two further patients a significant increase in tremor during the second five trials. The differences for four of these results gave $P<0.05$, and one a value of $P<0.01$. It was therefore concluded that bias due to practice or fatigue was slight in any consideration of the entire series of the results.

The effect of a series of different weights on intention tremor exhibited by eight patients (Table 3) shows the significance of the difference between tremor recordings made with and with-

TABLE 4

[COMPARISON OF OPTIMUM WEIGHT AND TREMOR SEVERITY

\begin{tabular}{ccc}
\hline Patient & Amount of lead $(g)$ & Tremor secerity* \\
\hline 1 & 600 & 3 \\
2 & 600 & 2 \\
3 & 840 & 2 \\
4 & 720 & 3 \\
5 & 720 & 1 \\
6 & 600 & 2 \\
7 & 720 & 3 \\
8 & 720 & 1 \\
\hline
\end{tabular}

* Graded as described in the text.

out weights, the results calculated on the square root transformations of the original data. Significant reduction of the tremor was obtained for all eight patients while wearing weights. Two patients showed significant reduction of tremor with all the weights tried, and for each patient an optimum effect was demonstrated with amounts of lead ranging from 600 to $840 \mathrm{~g}$. Table 4 shows the optimum amount of lead for each patient, and demonstrates that there was no apparent correlation between the optimum amount of lead required to reduce tremor, and the severity of the tremor in each case. One patient showed a significant reduction of the tremor which persisted after the weights had been removed. One patient exhibited a significant increase in the amount of tremor without weights in the final trials compared with that in the original trials. Comparison of the first five with the last five samples for each of the different 
trials with varying amounts of lead can be seen in Table 5. In the entire experiment only one patient showed a significant increase in the amount of tremor between the first and the last five samples, and this was during the final trial without weights. There was therefore no evidence that the weights produced any increase in fatigue during performance of the test, nor that fatigue was increased by the larger weights compared with the smaller weights used in the series. Conversely, there was no significant improvement in performance, again comparing the first five with the last five trials for each of the 10 samples recorded for each patient. Therefore, no practice effect was demonstrated, under the conditions of the experiment, in spite of the fact that the task was repeated many times by each patient.

\section{TABLE 5}

RESULTS OF ANALYSES TO INVESTIGATE EFFECT OF PRACTICE OR FATIGUE ON TREMOR MEASUREMENTS DURING $10 \mathrm{cON}$ SECUTIVE TRIALS WITH VARYING WEIGHTS

\begin{tabular}{cccccccc}
\hline Patients & $\begin{array}{c}\text { No } \\
\text { weights }\end{array}$ & $480 \mathrm{~g}$ & $600 \mathrm{~g}$ & $720 \mathrm{~g}$ & $840 \mathrm{~g}$ & $960 \mathrm{~g}$ & $\begin{array}{c}\text { No } \\
\text { weights }\end{array}$ \\
\hline 1 & 0.13 & 0.04 & 1.65 & 3.21 & 0.04 & 0.12 & 0.49 \\
2 & 0.01 & 5.30 & 2.72 & 0.68 & 2.84 & 0.01 & 4.11 \\
3 & 1.34 & 0.70 & 2.37 & 0.41 & 3.01 & 0.93 & 0.68 \\
4 & 2.87 & 0.35 & 0.01 & 0.58 & 0.99 & 2.53 & 0.50 \\
5 & 0.05 & 0.05 & 0.07 & 0.12 & 0.01 & 0.10 & $5.96 *$ \\
6 & 4.36 & 1.51 & 1.07 & 4.19 & 0.01 & 0.14 & 1.63 \\
7 & 0.21 & 0.57 & 1.91 & 3.27 & 1.81 & 0.09 & 0.79 \\
8 & 3.72 & 1.20 & 0.09 & 2.18 & 0.08 & 0.01 & 0.62 \\
\hline
\end{tabular}

In a comparison of the first five trials with the last five trials for each of the experimental conditions, the $F$ ratios to show the significance of the difference between groups are listed, and have been calculated from the square root transformation of the data.

* Significant, P less than 0.05 .

No apparent correlation between the pathological diagnosis and the effect of weights could be detected, but it was recognized that the numbers included in each of the diagnostic categories were small. Patients with a moderately severe or severe tremor were more likely to achieve benefit from the weights than those with either a mild or a very severe tremor. It was also noted that patients with a marked regular tremor which was noticeable when the arm was outstretched against gravity-for instance, in the patients with Parkinson's disease, and also in some of the patients with the familial essential tremors-tended to be less responsive than those with a pure intention tremor. None of the patients in this series had severe weakness, but it was noted that patients with moderate weakness, particularly of the proximal muscle groups, found it more tiring to wear the weights than those without such weakness.

\section{DISCUSSION}

The present study describes the application of an objective method of measuring tremor in a therapeutic trial which assessed the use of lead weights to reduce intention tremor. A clinical investigation into the possibility of using weights to diminish intention tremor has already been reported, with encouraging results (Hewer et al., 1972). However, these authors commented that clinical assessments, while being rapidly and easily available, may be too crude when, for example, comparisons of differing amounts of $\omega$ lead are required. It has now been shown that objective evaluations can overcome this difficulty $\frac{\rho}{1}$ 윽 and provide a way of analysing results to allow for the problem of variability. Such data also 3 enable more detailed assessments of other possibly significant factors, such as fatigue, $\stackrel{\circ}{\supset}$ which might affect these results. Confirmation $\overline{0} \overrightarrow{0}$ of a significant reduction of intention tremor ${ }^{\circ}$ ov with weights was obtained in this study, and further investigations showed that the effect was maximal for an optimum amount of lead, so that any further increase in weights produced a diminishing effect.

Holmes (1939) suggested that the delay in initiating movements, and the decreased velocity and acceleration noticed in patients with cerebellar lesions, could be partially attributable to the lack of a grading action of hypotonic antagonistic muscle, but was also probably in part due to a defect in post-inhibitory rebound, which Sherrington had shown facilitated transition of one movement to another in the opposite direction. Holmes also noted that if these patients carried a heavy bar, alternating movements of pronation and supination were improved in rate, rhythm, and range. He suggested that the weight increased the momentum of the limb and thus also the tension on the antagonists. This might help to overcome the defect in 
post-inhibitory rebound by an earlier excitation of succeeding contractions of antagonistic muscles.

An interesting observation by Chase et al. (1965) complicates this simple explanation. These authors noted marked attenuation of tremor in the supported hand of patients with an intention tremor, when weights up to a maximum of $100 \mathrm{~g}$ were applied. Under the conditions of their experiments, which clearly differed from those of the present study, attenuation of tremor was seen with an applied upward directed force, but not with a downward directed force. It was postulated that a critical change in the ratio of extensor to flexor muscle activity might account for these findings. The present series of results does not provide data on weights applied differentially to flexor or extensor surfaces, but the finding of a diminishing effect beyond an optimum amount of lead suggests that this theory may be only a partial explanation.

It can be argued that weights might reduce tremor by increasing the inertia of the system. Brumlik and Yap (1970) noted that the amplitude of normal rest tremor is progressively damped with weights up to $500 \mathrm{~g}$. However, once again the demonstration of an optimum amount of lead suggests that this explanation is also incomplete. In the present study weights did not attenuate the tremor exhibited by some patients with Parkinson's disease, nor some with an essential tremor, when these patients also had a marked rhythmic antigravity tremor. The experiments reported by Chase et al. (1965) also noted that patients with Parkinsonism were significantly less likely to show a reduction of tremor with applied force. These observations make it difficult to accept the theory that inertia is the only, or even the major factor, which explains the improved limb function. However, several differing mechanisms may be operative in a series of patients whose tremor arises from varying pathological lesions.

Experiments with normal subjects have shown that the addition of a large weight to the forearm impairs weight discrimination, and probably also therefore affects skilled tasks (Gregory and Ross, 1967). A significant time lapse is required for adaptation of the normal limb before there is a return of the status quo. It might be expected from the data that an abnormally functioning limb would also be affected transiently in a similar adverse manner, and that a time lapse would be required before adaptation occurred and before any improvement was noted. In fact, tremor reduction due to weights was seen at once, and no significant delay was detected in this study.

Holmes (1939) commented on the fact that any diversion of attention increased the irregularity of abnormal movements in a patient with intention tremor. The presence of lead weights increases the patient's awareness of the disabled limb, and possibly increases his concentration with resultant improved performance. If the improvement were related in any major part to attention and awareness, one might either expect a good initial response to weights and a diminishing response with time, or, as in the weight discrimination experiments, a delay before any improvement. In the short-term experiments reported here no such effects could be demonstrated.

It is likely that improved functional capacity achieved by the use of weights in patients with intention tremor is due to a variety of factors, which probably vary with the cause and hence the neurological lesion giving rise to the tremor. Investigations into the effect of agents which modify tremor may provide a better understanding of the impaired function, and this possibility is enhanced when objective and quantifiable methods of study are employed.

We are grateful to Miss E. H. L. Duncan, senior lecturer in medical statistics, University of Bristol, and to Mrs A. F. Morris, statistical assistant, Department of Community Medicine, University of Bristol, who gave considerable time and advice on the statistical analyses; to Mrs W. Clark for secretarial assistance, and to the South Western Regional Hospital Board for financial assistance.

\section{REFERENCES}

Brumlik, J., and Yap, C. B. (1970). Normal Tremor: a Comparative Study. Thomas: Springfield, Ill.

Chase, R. A., Cullen, J. K., Jr, Sullivan, S. A., and Ommaya, A. K. (1965). Modification of intention tremor in man. Nature, 206, 485-487.

Ferguson, G. A. (1966). Statistical Analysis in Psychology and Education. 2nd edn. McGraw-Hill: London.

Gregory, R. L., and Ross, H. E. (1967). Arm weight, adaptation, and weight discrimination. Perceptual and Motor Skills, 24, 1127-1130. 
Hewer, R. L., Cooper, R., and Morgan, M. H. (1972). An investigation into the value of treating intention tremor by weighting the affected limb. Brain, 95, 579-590.

Holmes, G. (1939). The cerebellum of man. Brain, 62, 1-30.

Morgan, M. H., Hewer, R. L., and Cooper, R. (1975).
Intention tremor-a method of measurement. Journal of Neurology, Neurosurgery, and Psychiatry. 38, 253-258.

Samra, K., Waltz, J. M., Riklan, M. Koslow, M., and Cooper, I. S. (1970). Relief of intention tremor by thalamic surgery. Journal of Neurology, Neurosurgery, and Psychiatry 33, 7-15. 